\title{
Distinguishing and treating depression, anxiety, adjustment, and post-traumatic stress disorders in brain tumor patients
}

\author{
Alec W. Gibson ${ }^{1,2}$, Jerome J. Graber ${ }^{3,4}$ \\ ${ }^{1}$ Department of Psychiatry and Behavioral Sciences, ${ }^{2}$ School of Medicine, ${ }^{3}$ Department of Neurology, ${ }^{4}$ Department of Neurological Surgery, \\ University of Washington, Seattle, WA, USA \\ Contributions: (I) Conception and design: All authors; (II) Administrative support: JJ Graber; (III) Provision of study materials or patients: All authors; \\ (IV) Collection and assembly of data: All authors; (V) Data analysis and interpretation: All authors; (VI) Manuscript writing: All authors; (VII) Final \\ approval of manuscript: All authors. \\ Correspondence to: Jerome J. Graber, MD, MPH. Department of Neurology, Alvord Brain Tumor Center, University of Washington, 1959 NE Pacific \\ Street, Seattle, WA 98105, USA. Email: jgraber@uw.edu.
}

\begin{abstract}
Cancer patients often suffer from psychiatric disorders as a result of their disease and its treatment. Rates of depression, anxiety, adjustment, and post-traumatic stress disorders are particularly high for individuals with cancer and differentiating between these conditions is important for providing both appropriate and high-quality care. Patients with primary and metastatic brain tumors are particularly susceptible to psychiatric morbidities as a result of direct neuropsychiatric effects from the tumor itself, as well as psychological distress stemming from their diagnosis, prognosis, or treatment. However, these morbidities are often underdiagnosed, misdiagnosed, and undertreated. Many tools exist for screening, diagnosing, and treating psychiatric disorders in brain tumor patients, and palliative care settings are well suited to both identify and treat psychiatric disorders in brain tumor patients. This review summarizes our current knowledge of psychiatric disorders in patients in patients with brain tumors, highlights the susceptibility of brain tumor patients to psychiatric conditions, provides recommendations for differentiating and treating these conditions, and emphasizes the need for further research. The goal of this review is to inform healthcare providers of the opportunities to address psychiatric morbidities in patients with primary and metastatic brain tumors, particularly in palliative care settings, and identify areas in need of additional research.
\end{abstract}

Koywords: Adjustment; anxiety; brain tumor; depression; post-traumatic stress disorder (PTSD)

Submitted Feb 29, 2020. Accepted for publication Jul 13, 2020.

doi: 10.21037/apm-20-509

View this article at: http://dx.doi.org/10.21037/apm-20-509

\section{Introduction}

Psychiatric disorders can have substantial implications for the health and well-being of cancer patients yet are often underdiagnosed and undertreated. Depression, anxiety, adjustment disorder (AD), and post-traumatic stress disorder (PTSD) can all occur as a result of cancer diagnosis, prognosis, treatment, and recurrence $(1,2)$. While some patients may have pre-existing mental health disorders or conditions unrelated to their cancer, many individuals suffer from psychiatric morbidities directly related to their cancer experience. Differentiating and treating these disorders across the cancer care continuum is critical to improving the quality of life for affected individuals. Palliative care settings are uniquely suited to integrate cancer care and mental health care, as well as provide screening and treatments of psychiatric disorders in cancer patients and their caregivers (3). In some cases, the

^ ORCID: 0000-0002-5709-4146. 
roles of palliative and psychiatric care may be more distinct. Through effective coordination, healthcare providers from multiple areas of medicine can ensure cancer patients with mental health conditions receive appropriate treatments, including spiritual care (4-6).

Patients with primary and metastatic brain tumors are particularly susceptible to psychiatric comorbidities. However, much is still unknown about the prevalence, causes, and effective treatments of these conditions in brain tumor patients. Psychiatric impairments can stem from the cancer care experience or from direct neuropsychiatric effects of the tumor and its treatment. In addition, brain tumor patients who experience mental health problems not only have diminished quality of life but can also have worse survival outcomes (7-10). This review provides an overview of depression, anxiety, AD, and PTSD in cancer patients and how to differentiate them in clinical settings. In addition, this review aims to summarize our current knowledge of psychiatric conditions specifically in brain tumor patients and methods for identifying and treating them.

\section{Psychiatric morbidities in cancer patients}

\section{Depression and anxiety}

Cancer patients suffering from depression or anxiety often have lower qualities of life, increased suicidal ideation, low medication and treatment adherence, impaired relationships with others, longer recovery time, and in some cases shorter survival (11-14). The prevalence of depression and anxiety disorders in the general population have been estimated to be approximately $5 \%$ and $7 \%$, respectively. However, in individuals treated for cancer the rates are much higher at $20 \%$ for depression and $10 \%$ for anxiety $(13,15)$. In palliative care settings specifically, $25 \%$ of cancer patients have a depression disorder and $10 \%$ are noted to have anxiety, although rates for inpatient palliative care can be as high as $48 \%$ for depression and $34 \%$ for anxiety $(13,16)$. Rates of depression and anxiety vary depending on the type of cancer, prognosis, and treatment, but it is estimated that the vast majority of cancer patients with depression do not receive treatment from a mental healthcare provider (17-19). Caregivers for cancer patients are also at risk. One study found that $29 \%$ of caregivers of cancer patients in palliative care settings had depression, while 39\% had anxiety. These levels were significantly reduced several months after the patient's death, and risk factors included high distress levels at the start of palliative care, poor social support, impaired physical function, and being a patient's spouse (20).

Psychological distress related to cancer diagnosis, treatment, prognosis, and even survivorship can have profound effects on mental health and subsequently manifest as depression or anxiety $(1,17,21)$. Alternatively, depression and anxiety can be attributed to the direct neuropsychiatric effects of the cancer or its treatment. Indeed, certain tumors can induce mood dysfunction due to their location, production of hormones and cytokines, or disruption of homeostasis. Treatments such as chemotherapy, steroids, radiation, and surgery can also result in symptoms of depression and anxiety (1,22-27). Cancer patients most at risk for developing depression appear to be younger, have functional limitations, and lack social support, while risk factors for anxiety include past trauma, demoralization, and metastasis for certain cancers. A history of psychiatric disorders puts patients at high risk for both conditions following a cancer diagnosis $(1,18$, 28-32). Cancer patients from certain marginalized populations face a particularly large risk for psychiatric conditions. For example, lesbian, gay, bisexual, transgender, and queer (LGBTQ) cancer patients experience greater levels of isolation and depression and less targeted counseling compared to heterosexual and cisgender patients. Hispanic and low-income cancer patients also experience particularly high levels of distress, anxiety, and depression (33-37).

Treatment of depression or anxiety in cancer patients should follow standard clinical guidelines, but it is important to note that some psychiatric medications are contraindicated with certain cancers, chemotherapies, and anesthetics (1). Specific interactions between psychiatric, antiemetic, and anticancer drugs, as well as potential side effects of antidepressants in cancer patients have been extensively reviewed elsewhere (38-42). Interventions aimed at psychiatric treatment can be performed by palliative care providers, and palliative care itself can be therapeutic. For advanced cancer patients with depression, early palliative care can significantly reduce mortality risk, and psychotherapy in palliative care settings can reduce symptoms of both depression and anxiety and improve quality of life (3,43-46). Despite this evidence, a majority of palliative care physicians report difficulty managing anxiety and accessing psychological or psychiatric services. This is particularly true for marginalized and minority cancer patients. In addition, research has shown redundancy and lack of consistency in the management of psychological distress by palliative care teams $(34,46-48)$. 


\section{$A D$}

$\mathrm{AD}$ is characterized by abnormally severe distress and maladaptive behavior, often accompanied by depression and/or anxiety, that is out of proportion to the intensity of a stressful life event. While most cancer patients experience distress, people with $\mathrm{AD}$ have difficulty adjusting to and managing their diagnosis, and typically respond with extreme emotions that impair their personal and social functioning $(49,50)$. Onset of $\mathrm{AD}$ occurs within 6 months of a stressful event and typically subsides after 6 months, and cases of $\mathrm{AD}$ are often more acute and situational relative to severe psychopathologies like PTSD but can manifest chronically as well. Symptoms of AD are not enough to warrant the diagnosis of a full anxiety or depression disorder, but can significantly reduce quality of life for affected individuals and can even increase cancer-specific mortality (49-52).

$\mathrm{AD}$ is highly prevalent in patients with cancer and is the psychiatric morbidity most often reported in this population $(11,49,50)$. A meta-analysis of over 10,000 cancer patients in hematological and oncological settings revealed an $\mathrm{AD}$ prevalence of $19.4 \%$ (13), although specific studies estimate a higher prevalence ranging from $25-35 \%$ (49,53-56). In palliative care settings, the rate of $\mathrm{AD}$ for cancer patients is similar at $15.4 \%(13)$. Women are twice as likely to present with $\mathrm{AD}$, and higher education has been found to be the most influential predictor for $\mathrm{AD}$ in cancer patients. Additionally, patients with metastatic disease have an $80 \%$ higher risk of developing $\mathrm{AD}$ compared to those with nonmetastatic cancer (57). In caregivers of cancer patients, rates of $\mathrm{AD}$ range from $13 \%$ to $58 \%$. Despite this, the psychiatric needs of caregivers are often overlooked and more research is needed to examine $\mathrm{AD}$ in this group $(58,59)$.

Cancer patients often experience distress and anxiety as a normal part of coping with their disease, which can make it difficult to determine when these emotions become excessive and characteristic of AD. Furthermore, there is a danger of pathologizing normal distress following a cancer diagnosis, and previous studies may be guilty of this (60). Further work is needed to more clearly resolve differences between normal reactions and AD. Symptoms of AD can be precipitated by a combination of normal distress and the pathological features of the cancer or treatment, such as the anxiogenic effects of steroids and tumor secretions $(1,61)$. Counseling on an individual and group basis can reduce symptoms of $\mathrm{AD}$ for cancer patients, and effective interventions include cognitive behavioral therapy (CBT), mediation/relaxation training, and hypnotherapy. If patients do not respond to psychotherapy, psychiatric medications similar to those used for anxiety and depression can also be used to address symptoms. Overall, psychiatric intervention can improve symptoms of $\mathrm{AD}$ in cancer patients and more studies are needed to identify the most effective treatments for treating cancer-related $\mathrm{AD}$, particularly in palliative care settings $(1,49,50,61-65)$.

\section{PTSD}

In addition to the intense emotional stress associated with cancer in general, many patients experience significant trauma as a result of their diagnosis or treatment. The shocking discovery of their disease, the realization of their mortality, and the initial overwhelming process of medical decision making can all lead to PTSD following an individual's diagnosis $(2,66,67)$. Subsequent treatments often cause emotional and physical pain, and even after achieving remission many patients have chronic fear of disease recurrence $(2,68)$. As a result, the experiences following diagnosis can also contribute to PTSD symptoms. Several studies have shown that approximately half of cancer patients feel that their diagnosis and treatment were traumatic experiences (2,69-72).

The percentage of cancer patients with PTSD ranges between $7.3 \%$ and $13.8 \%$ based on self-reported symptoms, while data from structured clinical interviews estimate a lifetime prevalence of $12.6 \%$ and a current prevalence of $6.4 \%$ (73). An additional subset of cancer patients may experience subsyndromal PTSD, which can also result in a lower quality of life and social impairments (74). Patients at greatest risk for developing PTSD are younger, have recently undergone treatment, have advanced disease, have a history of prior trauma, or have a family or personal history of psychiatric disease $(2,73,75)$. Many risk factors mirror those for non-cancer-related PTSD such as poor social support and peritraumatic dissociation $(2,75)$. Biological factors may also play a role in cancer-related PTSD. Numerous studies have linked glucocorticoid dysregulation and cortisol levels with PTSD (2,76-79); however, there is little work specifically focused on the biology of cancerrelated PTSD and more research is needed in order to draw definitive conclusions.

Rates of post-traumatic stress symptoms (PTSS) and PTSD are even higher for caregivers of cancer patients and vary depending on type of cancer and relationship with the patient. Spouses and parents of patients are most 
severely affected (80-83). One study found that $18.7 \%$ of caregivers of advanced cancer patients screened positive for PTSD (82), and rates of PTSS ranging from $25.7 \%$ to $36.8 \%$ have been reported for caregivers of leukemia and head and neck cancer patients $(81,83,84)$. Caregivers who perceive numerous symptoms and little treatment benefit for patients, use avoidant coping strategies, or have a prior history of patient-related trauma are at greatest risk for PTSS or PTSD $(85,86)$.

Although psychiatric medications including antidepressants, anxiolytics, and benzodiazepines can be used for symptom management, research focused on the use of these medications to treat cancer-related PTSD is lacking $(1,2)$. CBT is an effective treatment for cancerrelated PTSD, more so than supportive therapy, and can reduce symptoms of PTSD in patients with different types of cancer (87-89). Other behavioral and psychological therapies that can be effective for treating PTSD in cancer patients include supportive expressive group therapy, cognitive behavioral stress management, and eye movement desensitization and reprocessing (2,90-92). Regular palliative care interventions that address both physical and psychological distress can directly improve symptoms of PTSD (77,93-95), although care must be taken to avoid exacerbating symptoms through mandatory informational and emotional support meetings (96).

\section{Differentiating psychiatric disorders in cancer patients}

There is a growing body of evidence that demonstrates a high prevalence of psychiatric morbidities associated with cancer. Most of this data comes from either selfreported questionnaires or structured clinical interviews. Questionnaires are useful for initial screening and estimating the prevalence of psychiatric conditions for various cancers; however, they can overestimate actual rates and rely solely on patient interpretations of questions $(51,73,97)$. Numerous studies have validated the clinical use of questionnaires, such as the PTSD Checklist Civilian Version (PCL-C), the Patient Health Questionnaire (PHQ), and the General Anxiety Disorder-7 (GAD-7) questionnaire for screening cancer patients (69,97-101). However, structured clinical interviews are the gold-standard for diagnosing cancer patients with depression, anxiety, AD, or PTSD $(2,51)$. Unlike questionnaires, clinical interviews can determine etiology and assess the exact nature and functional impact of symptoms. This is important for evaluating whether the disorder is directly related to a patient's cancer diagnosis or is a comorbid condition that developed separately before or during cancer care.

There is little data reporting the differentiation of anxiety, depression, $\mathrm{AD}$, and PTSD in cancer patients, and there are few studies that screen for both AD and PTSD $(2,51)$. The $5^{\text {th }}$ edition of the Diagnostic and Statistical Manual of Mental Disorders (DSM-5) categorizes both $\mathrm{AD}$ and PSTD as "Trauma and Stress-Related Disorders", and both disorders can have similar presentations (102). It is critical to differentiate these conditions in cancer patients due to their different etiologies, outcomes, and treatments (Table 1). Individuals with AD typically have more time-limited and less severe symptoms than individuals with PTSD. Indeed, a diagnosis of AD can be appropriate and should be considered for people with subsyndromal symptoms of PTSD or for people whose cancer diagnosis was not traumatic but who still experience excessive symptoms of anxiety or depression $(2,102)$. Most studies that describe specific psychiatric disorders in cancer patients do not address whether symptoms may be better explained by a different disorder. As such, careful diagnostic evaluations should be done to differentiate between psychiatric conditions (51). Further, substance abuse disorders are also common in cancer patients and should also be a consideration during psychiatric evaluation (103). The majority of palliative care settings do not routinely screen patients for substance abuse despite a high prevalence in palliative care populations (104).

Current diagnostic criteria for anxiety, depression, $\mathrm{AD}$, and PTSD can present challenges for screening and diagnosis. According to the DSM-5 criterion A for PTSD, the traumatic event that results in the disorder involves "exposure to actual or threatened death, serious injury, or sexual violence" but notes that "a life-threatening illness or debilitating medical condition is not necessarily considered a traumatic event. Medical incidents that qualify as traumatic events involve sudden, catastrophic events" (102). This statement can cause debate about whether the diagnosis of cancer meets the criterion, and there are no studies that examine whether failure to meet this criterion affects the proportion of cancer patients with PTSD since the majority of research to date has used DSM-IV criteria. Criterion A also excludes caregivers who learn of a patient's cancer. Even if an individual does not meet criterion A they can still be diagnosed with PTSD if they meet multiple other criteria: at minimum one intrusion symptom (criterion B), one avoidance symptom (criterion C), two negative cognitive and/or dissociation symptoms (criterion D), and two arousal and reactivity symptoms 
Table 1 Distinguishing features and prevalence of psychiatric disorders in cancer patients

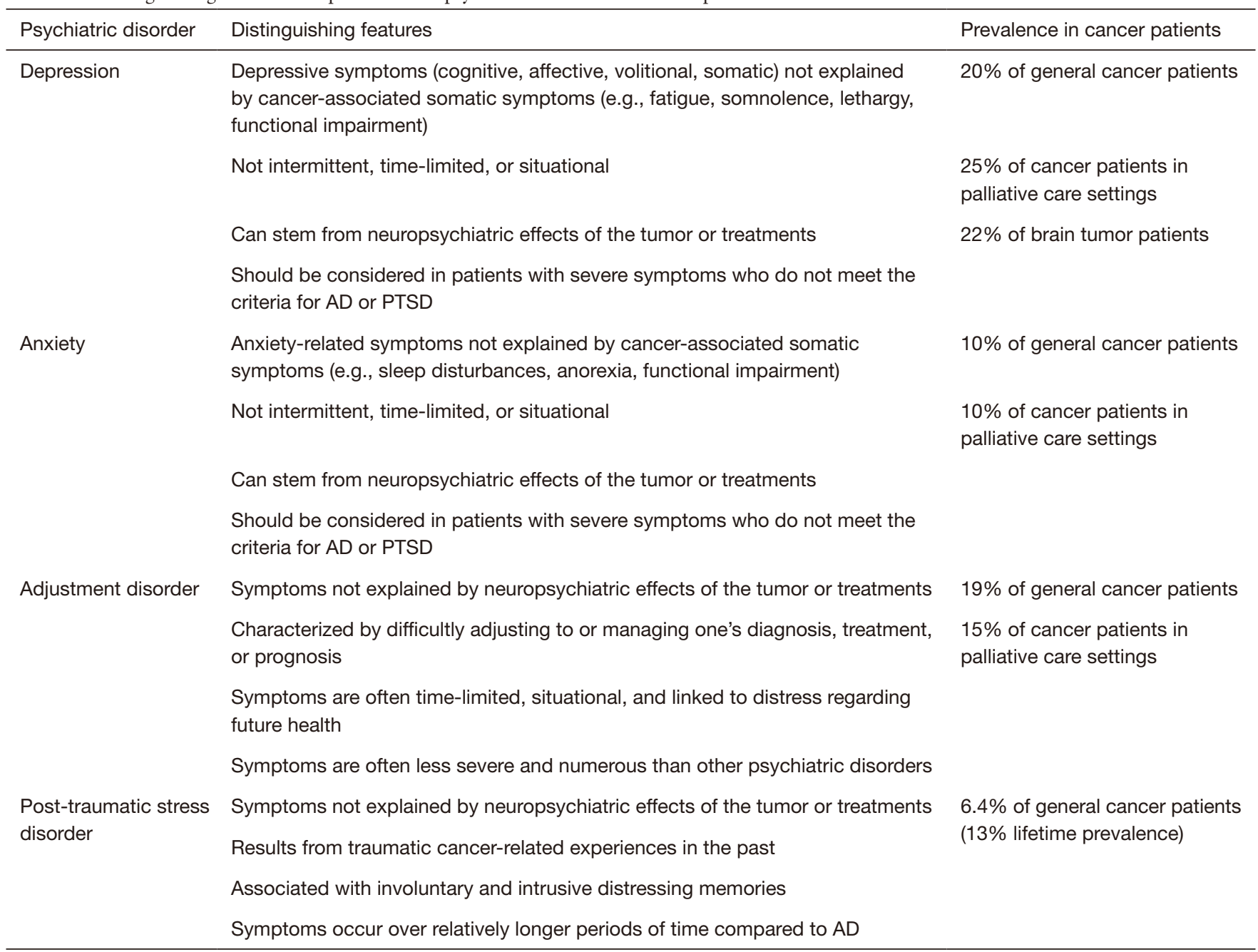

$\mathrm{AD}$, adjustment disorder; PTSD, post-traumatic stress disorder.

(criterion E). Symptoms must all be present for at least one month (criterion F) and cause substantial distress and impairment (criterion G). These criteria are stricter than DSM-IV criteria and will likely result in a lower reported prevalence of PTSD in relation to other psychiatric disorders over time. Further, the DSM- 5 states that AD is common with medical illness and can be the predominant response to an illness (102). If a patient does not have "involuntary and intrusive distressing memories" (criterion B) but rather experiences anxiety or fear regarding their future well-being, which seems to be the case for many cancer patients (105), they should be considered for cancer-related $\mathrm{AD}$ or anxiety rather than PTSD.

Symptoms that meet the criteria for $\mathrm{AD}$ are vague and somewhat non-specific. Consequently, it can be difficult to differentiate between normal and excessive distress for cancer patients. Symptoms of anxiety and depression can be components of $\mathrm{AD}$, which obfuscates the distinction between $\mathrm{AD}$ and generalized anxiety or depression disorders for patients who experience distress about their future health $(106,107)$. Thus, careful clinical evaluation is needed to achieve an accurate diagnosis of AD. Stressful life events such as cancer diagnoses and treatments can result in all of the aforementioned disorders, but direct neuropsychiatric effects of cancer or treatments themselves exclude diagnoses like AD and PTSD (2). The DSM-5 criteria for depression disorders also excludes symptoms directly related to medical conditions, which poses a problem for diagnosing cancer patients and has led some to call for a change in these criteria to better address cancer- 
related depression $(2,11,102)$. In palliative care settings, somatic symptoms such as fatigue, functional impairment, and sleep disturbances associated with cancer can further hamper the identification of depression in advanced stages of cancer. Several screening tools exist for identifying and distinguishing depression, such as packages and guidelines from the European Palliative Care Research Collaborative and the PHQ-2, 4, and $9(2,11,99,100,108)$. The National Comprehensive Cancer Network (NCCN) also provides a distress thermometer and guidelines for identifying and managing distress-related conditions prior to formal psychiatric evaluations (109-111). Integration of cancer and psychiatric care is key to ensuring appropriate diagnoses and treatments, particularly since most cancer patients are unable or unwilling to seek additional and separate mental healthcare $(2,112)$. Palliative care settings provide an opportunity to facilitate this integration. Ultimately, healthcare providers may use the presence or absence symptoms to exclude psychiatric disorders in order to distinguish between these conditions.

For caregivers of cancer patients, it is important to differentiate psychiatric conditions from other processes such as anticipatory grief, bereavement, and demoralization. Anticipatory grief is the process of dealing with an impending loss, including mourning and planning, while bereavement occurs when an individual loses a significant other (113). Both anticipatory grief and bereavement can be accompanied by emotional distress, depressive symptoms, separation anxiety, and functional impairment. As such, care should be taken to differentiate these processes from more severe psychiatric disorders. Several screening tools exist that help identify grief-related issues, including the Caregiver Grief Scale (CGS) and Prolonged Grief Disorder Questionnaire (PG-D), and treatments include psychoeducation and psychotherapy (e.g., CBT), which should be tailored to caregivers' specific situations (113). Demoralization occurs in $13-18 \%$ of patients diagnosed with a progressive disease or cancer (114). It is a condition characterized by feelings of hopelessness/helplessness, loss of meaning/purpose in life, reduced coping, and social isolation; consequently, patients who experience demoralization often have a desire for hastened death $(115,116)$. While demoralization and other psychiatric disorders such as depression share similar symptoms, demoralization can be distinguished based on a lack of anhedonia, improvement of mood with positive emotional experiences, and a lack of response to medications (114-116). Thus, psychotherapeutic interventions are the most effective treatment for demoralization, and screening tools exist to specifically identify this condition in cancer patients $(114,115)$.

\section{Susceptibility of brain tumor patients to psychiatric morbidities}

Patients with both primary and metastatic brain tumors exhibit high rates of psychosocial distress. The estimated prevalence of brain tumor patients suffering from cancerrelated distress or psychiatric disorders ranges from $38-48 \%$, with common diagnoses of $\mathrm{AD}$, anxiety, and depression. Patients frequently report the initial tumor detection as their most distressing experience, and these psychiatric conditions dramatically reduce quality of life (100,117-120). A meta-analysis of over 4,500 brain tumor patients estimated that the prevalence of depression alone is $22 \%$, although rates of self-reported symptoms of depression are much higher, and depressive symptoms are associated with shorter survival in patients with glioblastoma (7-10). Suicidal ideation occurs in $6 \%$ of patients undergoing surgery for brain tumors and is another concern for healthcare providers (121). Partners of brain tumor patients have high rates of psychiatric morbidities as well (47\%), the majority of whom report that their distress stems from fear of surgical outcomes (117). Experience with brain tumors can also be a traumatic experience. Thirty-five percent of pediatric brain tumor survivors and $29 \%$ of their parents have severe levels of PTSS (122), but there is a scarcity of research focused on brain tumor-related PTSS or PTSD in adults. Due to the nature of their disease, brain tumor patients are particularly susceptible to neuropsychiatric symptoms that result directly from the cancer and its treatment (Table 2). Interestingly, the rate of mental health disorders for central nervous system (CNS) cancer patients begins to increase as early as 10 months before their diagnosis, increases rapidly and peaks the week after diagnosis, and remains elevated 8-10 years after diagnosis. Compared to cancer-free individuals, the use of psychiatric medications begins to increase approximately one month before diagnosis, rapidly increases around the time of diagnosis, peaks approximately 3 months after diagnosis, and remains elevated 2 years after diagnosis. Peak use of psychiatric medications is particularly high for patients with cancers of the CNS compared to other cancers (123).

Brain tumors can alter the structure and function of regions critical for regulating emotional state, personality, 
Table 2 Neuropsychiatric effects of brain tumors, symptoms, and their treatments

\begin{tabular}{|c|c|c|}
\hline Cause & Neuropsychiatric effect & Recommendations \\
\hline Temporal lobe tumors & Epilepsy, panic & Treat/debulk tumor, antiseizure medications \\
\hline Pituitary tumors & $\begin{array}{l}\text { HPA axis dysfunction, depression, } \\
\text { anxiety }\end{array}$ & $\begin{array}{l}\text { Check HPA axis, treat hormonal dysregulation, treat/ } \\
\text { debulk tumor }\end{array}$ \\
\hline Tumor-related seizures & Depression, anxiety & Antiseizure medications, antidepressants/anxiolytics \\
\hline Glucocorticoids & $\begin{array}{l}\text { Depression, anxiety, dysphoria, mania, } \\
\text { delirium, insomnia, increased appetite, } \\
\text { cognitive impairment }\end{array}$ & $\begin{array}{l}\text { Rotate steroids, alter steroid dose or type, } \\
\text { antipsychotics }\end{array}$ \\
\hline Brain radiotherapy & $\begin{array}{l}\text { HPA axis dysfunction, mood } \\
\text { alterations, depression, anxiety }\end{array}$ & $\begin{array}{l}\text { Check HPA axis, treat hormonal dysregulation, } \\
\text { antidepressants/anxiolytics }\end{array}$ \\
\hline
\end{tabular}

HPA, hypothalamic-pituitary-adrenal.

and behaviors $(124,125)$. These tumors, as well as associated edema, can also induce neuroinflammatory reactions that are associated with various psychiatric conditions including depression and anxiety (126-128). Tumor location can influence the types of psychiatric symptoms patients experience. Frontal lobe tumors have been linked to depression and apathy, and temporo-limbic tumors can cause panic attacks. Tumor-associated temporal lobe epilepsy can be misdiagnosed as a panic disorder, and it is important to recognize the potential psychiatric presentations of both frontal and temporal lobe brain tumors $(10,129)$. Some studies failed to show an effect of tumor location on the incidence of depression; however, the size of tumors does seem to influence mood dysfunction. Tumors with diameters larger than $4 \mathrm{~cm}$ are associated with higher rates of depression (10). Affective symptoms are also related to the integrity of white matter tracts in brain tumor patients, which can be visualized with diffusion tensor imaging (130). Finally, the type of tumor can play a role in the development of psychiatric morbidities. Pituitary tumors can cause depression and anxiety via hormonal dysregulation and alterations to the hypothalamic-pituitaryadrenal (HPA) axis. HPA axis dysfunction is often associated with increased secretion of corticotropin releasing hormone (CRH) and/or adrenocorticotropic hormone (ACTH), which results in abnormally high levels of glucocorticoids and catecholamines that can be detrimental to mental and physical health. Both neurosurgical and radiation treatments of tumors can also induce HPA axis dysfunction in 22-65\% of patients (131). Laboratory tests can identify HPA axis dysfunction, and patients can also present with physical and mental changes (e.g., Cushing's syndrome) that can further aid diagnosis (132). Excessive ACTH and growth hormone secretion from pituitary tumors can result in depression rates of $63 \%$ and $75 \%$, respectively, while excess prolactin secretion causes more anxiety-related symptoms $(10,133)$. Patients with meningiomas seem to have a higher prevalence of depression (30\%) compared to other tumors like gliomas and vestibular schwannomas, although these tumors also have higher depression rates compared to the general population (10). It is important to note that certain tumors, such as those located in the thalamus, basal ganglia, or reticular formation, can present with symptoms of fatigue, lethargy, somnolence, or apathy that can mimic symptoms of depression $(10,134)$.

Cognitive impairment is one of the most common presenting symptoms of brain tumor patients. Primary and metastatic tumors can invade and compress brain regions critical for executive function, attention, memory, and emotional regulation. Edema associated with brain tumors can also result in cognitive deficits and other somatic symptoms such as fatigue and headaches $(124,125)$. The 
prevalence and type of cognitive impairment varies widely depending on tumor location, size, type, and the cognitive domain tested (e.g., memory versus attention). Rates of cognitive impairment as high as $83 \%$ have been reported for glioma patients, and $92 \%$ of brain tumor patients in general have been shown to have episodic memory deficits (125,135-138). Treatment of brain tumors can also have a profound effect on cognitive function. In some cases, treatment can be a greater risk factor for impairment than tumor location, and adverse cognitive effects following chemotherapy and radiotherapy for brain tumors have been particularly well-described (137,139-141). Mental deficits can lead to emotional dysfunction, and cognitive impairment is associated with both anxiety and depression in patients with brain tumors (142-145). In addition, many patients with brain tumors experience sleep dysfunction, which can also contribute to the development of depression (10). At the same time, associated symptoms of cognitive impairment such as fatigue, somnolence, and lack of interest in activities can be confused with or mask symptoms of depression. Patients with cognitive impairment and dementia also experience high fall rates which can result in serious injuries (146).

A majority of individuals with brain tumors experience seizures as a result of their disease. In fact, cognitive impairment and seizures are the most common symptoms in patients with primary brain tumors and more commonly present in patients with brain tumors compared to other cancers $(137,147,148)$. Low grade and primary tumors are more likely to cause seizures than high grade or metastatic tumors, with epilepsy rates as high as $85 \%$ for low-grade glioma (149-151). Although complete overview of epilepsy and psychiatric disorders is outside the scope of this review, there have been numerous studies demonstrating a relationship between seizures and conditions such as depression, anxiety, and PTSD (152). Patients with seizures show higher rates of comorbid psychiatric disorders, and levels of depression and anxiety strongly correlate with frequency of seizures (148,153-157). First-line treatment of seizures in brain tumor patients involves monotherapy with an antiseizure medication, and many patients are placed on medication as a prophylactic therapy. While some antiseizure medications like valproate, lamotrigine, and benzodiazepines are anxiolytic and can have positive effects on mood, others like levetiracetam, topiramate, and barbiturates can worsen mood and lead to depression, anxiety, or aggression (158-160). Additionally, 30-40\% of brain tumor patients experience side-effects from antiseizure medications, a higher incidence than in noncancer patients, so careful consideration of potential neuropsychiatric consequences is necessary when treating seizures in this population $(151,161)$. Antiseizure medications are not an appropriate substitute for formal psychiatric treatment, and psychiatric drugs are typically safe to use in conjunction with antiseizure medications at therapeutic doses. However, interactions can occur depending on the medication. Antiseizure drugs can alter the concentration of psychiatric medications in the plasma and vice versa, which can hinder the efficacy of these drugs or result in toxicity. At higher levels, psychiatric medications including selective serotonin reuptake inhibitors (SSRIs) and serotonin and norepinephrine reuptake inhibitors (SNRIs) can potentially lower the seizure threshold and display proconvulsive properties (162-164). As such, careful clinical monitoring is required when treating patients with seizures and psychiatric comorbidities.

Treatments for primary and metastatic brain tumors often come with increased risks of psychiatric complications. Glucocorticoids are routinely used to treat cerebral edema and increased intracranial pressure associated with brain tumors $(165,166)$. These steroids are effective but can induce numerous neuropsychiatric symptoms including depression, anxiety, dysphoria, mania, delirium, insomnia, increased appetite, and cognitive deficits (167-169). Many of these symptoms are addressed by standardized screening tools such as the PHQ. Depression has been particularly noted for brain tumor patients on steroids 6 months postsurgery (9). Patients with a personal or family history of depression or alcoholism have a higher risk of steroidinduced affective disorders, and higher doses of steroids cause more severe symptoms $(170,171)$. Chemotherapeutic agents used to treat a variety of brain cancers also have potential neuropsychiatric effects. For example, methotrexate and pemetrexed can cause mood alterations, vincristine and etoposide can produce depressive symptoms, and procarbazine can induce mania $(1,24,172)$. Procarbazine in particular has monoamine oxidase inhibitor (MAOI) activity which can cause interactions with antidepressants and other psychiatric medications. This MAOI activity can also result in severe interactions with tyraminecontaining foods, which should be avoided in patients taking procarbazine $(38,173)$. Partial and whole brain radiotherapy can result in depression, anxiety, and mood alterations which can be secondary consequences of postradiation hormonal deficiencies $(1,172,174)$. Neurosurgical interventions can result in emotional and behavioral 
changes depending on the site of resection. Decompression of brain regions that regulate emotional responses (e.g., limbic regions) can potentially alleviate affective symptoms. Additionally, some studies indicate that gross total resection can improve symptoms of depression (10). However, the act of undergoing surgery can itself cause distress and anxiety, and patients who adopt coping strategies that aid with emotional adjustment have better emotional responses than those who display excessive rumination $(1,172,175-177)$.

Finally, headaches are a common symptom in patients with brain tumors and are often treated with opioid analgesics $(178,179)$. Opioids have the potential to cause serotonin toxicity or serotonin syndrome which can result in altered mental status and numerous other symptoms, particularly when combined with psychiatric medications such as SSRIs/SNRIs. Consequently, other medications such as triptans have been recommended for headache treatment, which are safer to use for patients taking SSRIs/ SNRIs (180). The risk of serotonin syndrome with opioid medications should also be considered in cases of general pain management, particularly in palliative care settings.

\section{Diagnosing and treating psychiatric disorders in patients with brain tumors}

Depression and anxiety are the most well-studied psychiatric disorders in brain tumor patients and can occur across the cancer care continuum. Screening for depression and anxiety should be a routine and integrated component of cancer care. The NCCN's distress thermometer and other surveys such as the PHQ-2, PHQ-4, and GAD-7 are effective means for identifying symptoms of depression and anxiety in brain tumor patients $(99-101,181)$. Although screening is essential for identifying potential mental health conditions, structured clinical interviews and formal psychiatric evaluations should follow in order to make an appropriate diagnosis based on DSM-5 criteria and current guidelines. This is particularly important because somatic symptoms associated with brain tumors can mimic or mask symptoms of anxiety and depression. Many brain tumor patients experience fatigue, somnolence, functional limitations, or normal distress that are not associated or occur simultaneously with an affective disorder. It is also important to differentiate between neuropsychiatric symptoms that directly result from the tumor or cancer therapies themselves versus psychosocial causes of depression or anxiety, since diagnoses and treatments can differ based on symptom etiology $(1,9,10,124,125)$.
The symptoms for anxiety and depression are divergent enough to differentiate between these conditions during routine screening, but formal evaluation should be used to distinguish depression or anxiety disorders from other conditions such as $\mathrm{AD}$ or PTSD $(1,51)$.

The presence of certain risk factors can indicate the need for additional screening and evaluation. Large tumors (greater than $4 \mathrm{~cm}$ in diameter), pituitary tumors, and meningiomas all carry high risks of depression and anxiety symptoms. Cognitive impairment and seizures that result from brain tumors, along with treatments such as glucocorticoids, also put patients at risk $(9,10,133,142$ $145,148,154,159)$. From a psychosocial standpoint, cancer patients who are younger, have functional limitations, and lack social support are at increased risk for depression, while past trauma, demoralization, and metastasis can increase risk for anxiety. Cancer patients from certain marginalized and minority populations and patients with a history of mental health issues are also more likely to have cancer-related depression or anxiety $(1,18,28-34)$. Research focused on brain tumor patients specifically indicates that female gender, lower tumor grade, lower education level, and a history of psychiatric illness all predict anxiety and depression (182). Healthcare providers should be aware of these risk factors when screening brain tumor patients for depression and anxiety disorders.

Patients with symptoms of depression or anxiety that stem from their tumor or cancer therapy can sometimes benefit from treating the tumor itself or altering the causative therapy. Neurosurgical resection of brain tumors can alleviate neuropsychiatric symptoms by decompressing affected brain regions or removing hormone-secreting tumors. Alterations to the dose or type of medications that induce depression or anxiety symptoms can also provide relief. Patients who experience steroid-associated psychiatric morbidities may benefit from rotating the type of steroid used or treatment with antipsychotic medications such as risperidone (183). Healthcare providers should also check the HPA axis to monitor for potential hormonal causes of psychiatric symptoms, particularly in patients with pituitary tumors or individuals who receive radiotherapy. Restoring HPA axis balance could improve psychiatric symptoms. However, it may be beneficial or necessary to utilize psychiatric and psychological interventions in conjunction with cancer-targeted therapies $(1,9,10,164)$. Pharmacological treatment of depression and anxiety should follow normal standards of care for non-cancer patients, while avoiding interactions with chemotherapeutic and 
other cancer-related agents as described in previous reviews $(1,38-40,42)$. Although it is important to be cautious when treating brain tumor patients with psychiatric medications, they are relatively safe to use in cancer patients and the therapeutic benefit of medical intervention can be substantial (41). Thus, healthcare providers should consider the use of these drugs when warranted by a psychiatric diagnosis. Some studies have also demonstrated the success of psychedelics and ketamine for treating cancerrelated psychiatric distress, particularly in hospice settings (184-186). Evaluation of ketamine for treating depression in brain tumor patients is currently ongoing, but psychedelic or ketamine therapy may be additional options for brain cancer patients (187).

Psychosocial interventions also improve symptoms of depression and quality of life for brain tumor patients, and continued psychological care can reduce depression and anxiety levels while lowering seizure frequency $(188,189)$. Brain tumor patients who exhibit emotional stability and openness about their disease have less general depression and anxiety, while patients who integrate the disease into their identity and blame themselves experience more depression $(190,191)$. Neurosurgical patients who employ optimism and trust as coping strategies have less surgery-related anxiety and better emotional wellbeing. Conversely, excessive rumination results in greater surgery-related anxiety and psychiatric morbidity (177). Thus, interventions focused on helping brain tumor patients with their coping strategies and emotional responses can improve cancer-related mood disorders. Early interventions in palliative care settings can reduce depression and anxiety and enhance quality of life for brain tumor patients, and these settings are uniquely suited to integrate psychiatric screening and treatment with cancer care $(3,43-46,192)$.

Brain tumor patients with symptoms of depression or anxiety may suffer from cancer-related AD. AD is the most common psychiatric disorder in general cancer patients and is often associated with anxious or depressive behaviors $(13,49,50)$. Therefore, psychiatric evaluations should be used to carefully differentiate between general depression or anxiety disorders and $\mathrm{AD}$ in patients with brain tumors. DSM- 5 criteria for $\mathrm{AD}$ are somewhat ambiguous and present challenges for clearly distinguishing $\mathrm{AD}$ from other psychiatric disorders in cancer patients $(102,106,107)$. In general, AD stems from problematic adjustment to or management of stressful life events such as the diagnosis or treatment of brain tumors, rather than direct neuropsychiatric consequences of the disease (although these consequences can contribute to the development of AD). Symptoms of AD are generally not severe enough to meet the criteria for general depression or anxiety disorders and are typically more acute and situational $(1,2,50-52,61,102)$. There is a lack of research focused on the differentiation of $\mathrm{AD}$ from other psychiatric disorders in brain tumor patients, as well as the risk factors for $\mathrm{AD}$ in this population. Data on more general cancer patient populations can provide insight for providers during screening for $\mathrm{AD}$ until further data become available. The majority of brain tumor patients suffering from psychiatric disorders, including $\mathrm{AD}$, report that the initial tumor detection is their most distressing experience (117). Therefore, screening for AD should take place early and continue throughout patients' cancer care. There are no studies to date that examine AD treatments for brain tumor patients, but research with general cancer patient populations indicate that CBT, relaxation interventions, and psychiatric medications for symptom management are effective therapies for cancer-related $\mathrm{AD}$ $(1,49,50,62-65)$.

The DSM-5 outlines specific criteria that enable the differentiation of PTSD from AD and general depression or anxiety disorders. In particular, cancer patients with PTSD are often burdened with uncontrolled and distressing cancer-related memories, rather than distress about their future which is more indicative of adjustment or anxiety disorders. Receiving cancer diagnoses, prognoses, and treatments can be traumatic and lead to distressing memories and other PTSD symptoms $(2,51,102)$. It is important to consider whether a brain tumor-related experience meets the formal classification of a traumatic event according to the DSM-5; however, brain tumor patents can still meet the criteria for PTSD even if their diagnosis or treatment is not considered "sudden" and "catastrophic". Brain tumor patients with PTSS but not formal PTSD should also be considered for an $\mathrm{AD}$ diagnosis $(51,102)$. Like $\mathrm{AD}$, PTSD in brain tumor patients is greatly understudied, and more work is needed to evaluate the traumatic nature of brain tumor diagnoses and treatments. Additionally, little is known about specific risk factors and effective treatments for PTSD in patients with CNS cancers. Cancer patients in general who have PTSD can benefit from CBT and other psychotherapies, as well as and palliative care interventions that address both physical and psychological distress (2,77,87-95). 


\section{Conclusions}

Depression, anxiety, adjustment, and PTSDs are prevalent in cancer patients and can significantly reduce their quality of life. Individuals with brain tumors are particularly susceptible to psychiatric morbidities as a result of their disease. Screening for psychiatric morbidities should take place across the cancer care continuum, and palliative care settings are uniquely suited to differentiate and treat these conditions. Ultimately, more research is needed to fully understand and address the needs of brain tumor patients with psychiatric disorders.

\section{Acknowledgments}

Funding: None.

\section{Footnote}

Provenance and Peer Review: This article was commissioned by the editorial office, Annals of Palliative Medicine for the series "Palliative Care in Neuro-Oncology". The article has undergone external peer review.

Peer Review File: Available at http://dx.doi.org/10.21037/ apm-20-509

Conflicts of Interest: Both authors have completed the ICMJE uniform disclosure form (available at http://dx.doi. org/10.21037/apm-20-509). The series "Palliative Care in Neuro-Oncology" was commissioned by the editorial office without any funding or sponsorship. JJG served as the unpaid Guest Editor of the series. AWG has no other conflicts of interest to declare.

Ethical Statement: The authors are accountable for all aspects of the work in ensuring that questions related to the accuracy or integrity of any part of the work are appropriately investigated and resolved.

Open Access Statement: This is an Open Access article distributed in accordance with the Creative Commons Attribution-NonCommercial-NoDerivs 4.0 International License (CC BY-NC-ND 4.0), which permits the noncommercial replication and distribution of the article with the strict proviso that no changes or edits are made and the original work is properly cited (including links to both the formal publication through the relevant DOI and the license).
See: https://creativecommons.org/licenses/by-nc-nd/4.0/.

\section{References}

1. Pitman A, Suleman S, Hyde N, et al. Depression and anxiety in patients with cancer. BMJ 2018;361:k1415.

2. Cordova MJ, Riba MB, Spiegel D. Post-traumatic stress disorder and cancer. Lancet Psychiatry 2017;4:330-8.

3. Prescott AT, Hull JG, Dionne-Odom JN, et al. The role of a palliative care intervention in moderating the relationship between depression and survival among individuals with advanced cancer. Health Psychol 2017;36:1140-6.

4. Riordan P, Briscoe J, Kamal AH, et al. Top Ten Tips Palliative Care Clinicians Should Know About Mental Health and Serious Illness. J Palliat Med 2018;21:1171-6.

5. Trachsel M, Irwin SA, Biller-Andorno N, et al. Palliative psychiatry for severe and persistent mental illness. Lancet Psychiatry 2016;3:200.

6. Rego F, Nunes R. The interface between psychology and spirituality in palliative care. J Health Psychol 2019;24:279-87.

7. Huang J, Zeng C, Xiao J, et al. Association between depression and brain tumor: a systematic review and metaanalysis. Oncotarget 2017;8:94932-43.

8. Noll KR, Sullaway CM, Wefel JS. Depressive symptoms and executive function in relation to survival in patients with glioblastoma. J Neurooncol 2019;142:183-91.

9. Litofsky NS, Farace E, Anderson F Jr, et al. Depression in patients with high-grade glioma: results of the Glioma Outcomes Project. Neurosurgery 2004;54:358-66; discussion 366-7.

10. Litofsky NS, Resnick AG. The relationships between depression and brain tumors. J Neurooncol 2009;94:153-61.

11. Caruso R, Nanni MG, Riba MB, et al. The burden of psychosocial morbidity related to cancer: patient and family issues. Int Rev Psychiatry 2017;29:389-402.

12. Mehta RD, Roth AJ. Psychiatric considerations in the oncology setting. CA Cancer J Clin 2015;65:300-14.

13. Mitchell AJ, Chan M, Bhatti H, et al. Prevalence of depression, anxiety, and adjustment disorder in oncological, haematological, and palliative-care settings: a meta-analysis of 94 interview-based studies. Lancet Oncol 2011;12:160-74.

14. Chang CK, Hayes RD, Broadbent MT, et al. A cohort study on mental disorders, stage of cancer at diagnosis and subsequent survival. BMJ Open 2014;4:e004295.

15. Steel Z, Marnane C, Iranpour C, et al. The global 
prevalence of common mental disorders: a systematic review and meta-analysis 1980-2013. Int J Epidemiol 2014;43:476-93.

16. Buzgova R, Jarosova D, Hajnova E. Assessing anxiety and depression with respect to the quality of life in cancer inpatients receiving palliative care. Eur J Oncol Nurs 2015;19:667-72.

17. Smith HR. Depression in cancer patients: Pathogenesis, implications and treatment (Review). Oncol Lett 2015;9:1509-14.

18. Walker J, Hansen CH, Martin P, et al. Prevalence, associations, and adequacy of treatment of major depression in patients with cancer: a cross-sectional analysis of routinely collected clinical data. Lancet Psychiatry 2014;1:343-50.

19. Linden W, Vodermaier A, Mackenzie R, et al. Anxiety and depression after cancer diagnosis: prevalence rates by cancer type, gender, and age. J Affect Disord 2012;141:343-51.

20. Gotze H, Brahler E, Gansera L, et al. Anxiety, depression and quality of life in family caregivers of palliative cancer patients during home care and after the patient's death. Eur J Cancer Care (Engl) 2018;27:e12606.

21. Hoffman KE, McCarthy EP, Recklitis CJ, et al. Psychological distress in long-term survivors of adultonset cancer: results from a national survey. Arch Intern Med 2009;169:1274-81.

22. Holland JC, Korzun AH, Tross S, et al. Comparative psychological disturbance in patients with pancreatic and gastric cancer. Am J Psychiatry 1986;143:982-6.

23. Breitbart W, Rosenfeld B, Tobias K, et al. Depression, cytokines, and pancreatic cancer. Psychooncology 2014;23:339-45.

24. Wick W, Hertenstein A, Platten M. Neurological sequelae of cancer immunotherapies and targeted therapies. Lancet Oncol 2016;17:e529-e541.

25. Cherrier MM, Aubin S, Higano CS. Cognitive and mood changes in men undergoing intermittent combined androgen blockade for non-metastatic prostate cancer. Psychooncology 2009;18:237-47.

26. Snijders-Keilholz A, Griffioen G, Davelaar J, et al. Vitamin B12 malabsorption after irradiation for gynaecological tumours. Anticancer Res 1993;13:1877-81.

27. Rocca WA, Grossardt BR, Geda YE, et al. Long-term risk of depressive and anxiety symptoms after early bilateral oophorectomy. Menopause 2008;15:1050-9.

28. Vodermaier A, Linden W, MacKenzie R, et al. Disease stage predicts post-diagnosis anxiety and depression only in some types of cancer. Br J Cancer 2011;105:1814-7.

29. Die Trill M. Anxiety and sleep disorders in cancer patients. EJC Suppl 2013;11:216-24.

30. Stark DP, House A. Anxiety in cancer patients. Br J Cancer 2000;83:1261-7.

31. Bevilacqua LA, Dulak D, Schofield E, et al. Prevalence and predictors of depression, pain, and fatigue in olderversus younger-adult cancer survivors. Psychooncology 2018;27:900-7.

32. An E, Lo C, Hales S, et al. Demoralization and death anxiety in advanced cancer. Psychooncology 2018;27:2566-72.

33. Gonzalez-Mercado VJ, Saligan LN, Ji M, et al. Differences in the Severity, Distress, Interference, and Frequency on Cancer-Related Symptoms Between Island Hispanic Puerto Ricans and Mainland Non-Hispanic Whites. J Immigr Minor Health 2018;20:1029-39.

34. Gibson AW, Radix AE, Maingi S, et al. Cancer care in lesbian, gay, bisexual, transgender and queer populations. Future Oncol 2017;13:1333-44.

35. Lee MS, Tyson DM, Gonzalez BD, et al. Anxiety and depression in Spanish-speaking Latina cancer patients prior to starting chemotherapy. Psychooncology 2018;27:333-8.

36. Crane TE, Badger TA, Sikorskii A, et al. Trajectories of Depression and Anxiety in Latina Breast Cancer Survivors. Oncol Nurs Forum 2019;46:217-27.

37. Oh H, Ell K, Subica A. Depression and family interaction among low-income, predominantly hispanic cancer patients: a longitudinal analysis. Support Care Cancer 2014;22:427-34.

38. Yap KY, Tay WL, Chui WK, et al. Clinically relevant drug interactions between anticancer drugs and psychotropic agents. Eur J Cancer Care (Engl) 2011;20:6-32.

39. Chan A, Ng TR, Yap KY. Clinically-relevant anticancerantidepressant drug interactions. Expert Opin Drug Metab Toxicol 2012;8:173-99.

40. Miguel C, Albuquerque E. Drug interaction in psycho-oncology: antidepressants and antineoplastics. Pharmacology 2011;88:333-9.

41. Grassi L, Nanni MG, Rodin G, et al. The use of antidepressants in oncology: a review and practical tips for oncologists. Ann Oncol 2018;29:101-11.

42. Saylor MS, Smetana RF. Potential for drug-drug interactions in treating cancer-related nausea and distress. J Oncol Pharm Pract 2011;17:403-8.

43. Okuyama T, Akechi T, Mackenzie L, et al. Psychotherapy for depression among advanced, incurable cancer patients: 
A systematic review and meta-analysis. Cancer Treat Rev 2017;56:16-27.

44. Fulton JJ, Newins AR, Porter LS, et al. Psychotherapy Targeting Depression and Anxiety for Use in Palliative Care: A Meta-Analysis. J Palliat Med 2018;21:1024-37.

45. Lloyd-Williams M, Shiels C, Ellis J, et al. Pilot randomised controlled trial of focused narrative intervention for moderate to severe depression in palliative care patients: DISCERN trial. Palliat Med 2018;32:206-15.

46. Kozlov E, Eghan C, Moran S, et al. Palliative Care Providers' Practices Surrounding Psychological Distress Screening and Treatment: A National Survey. Am J Hosp Palliat Care 2018;35:938-44.

47. Atkin N, Vickerstaff V, Candy B. 'Worried to death': the assessment and management of anxiety in patients with advanced life-limiting disease, a national survey of palliative medicine physicians. BMC Palliat Care 2017;16:69.

48. von Blanckenburg P, Leppin N. Psychological interventions in palliative care. Curr Opin Psychiatry 2018;31:389-95.

49. Miovic M, Block S. Psychiatric disorders in advanced cancer. Cancer 2007;110:1665-76.

50. PDQ Supportive and Palliative Care Editorial Board. Adjustment to Cancer: Anxiety and Distress (PDQ(R)): Health Professional Version. PDQ Cancer Information Summaries. Bethesda (MD), 2002.

51. Kangas M. DSM-5 Trauma and Stress-Related Disorders: Implications for Screening for Cancer-Related Stress. Front Psychiatry 2013;4:122.

52. Lu D, Andrae B, Valdimarsdottir U, et al. Psychological distress is associated with cancer-specific mortality among patients with cervical cancer. Cancer Res 2019. [Epub ahead of print]. doi: 10.1158/0008-5472.CAN-19-0116.

53. Derogatis LR, Morrow GR, Fetting J, et al. The prevalence of psychiatric disorders among cancer patients. JAMA 1983;249:751-7.

54. Kirsh KL, McGrew JH, Dugan M, et al. Difficulties in screening for adjustment disorder, Part I: Use of existing screening instruments in cancer patients undergoing bone marrow transplantation. Palliat Support Care 2004;2:23-31.

55. Grabsch B, Clarke DM, Love A, et al. Psychological morbidity and quality of life in women with advanced breast cancer: a cross-sectional survey. Palliat Support Care 2006; 4:47-56.

56. Grassi L, Sabato S, Rossi E, et al. Affective syndromes and their screening in cancer patients with early and stable disease: Italian ICD-10 data and performance of the Distress Thermometer from the Southern European Psycho-Oncology Study (SEPOS). J Affect Disord 2009;114:193-9.

57. Hund B, Reuter K, Harter M, et al. Stressors, Symptom Profile, and Predictors of Adjustment Disorder in Cancer Patients. Results from an Epidemiological Study with the Composite International Diagnostic Interview, Adaptation for Oncology (Cidi-O). Depress Anxiety 2016;33:153-61.

58. Asai M, Akechi T, Nakano T, et al. Psychiatric disorders and background characteristics of cancer patients' family members referred to psychiatric consultation service at National Cancer Center Hospitals in Japan. Palliat Support Care 2008;6:225-30.

59. Lee Y, Lin PY, Chien CY, et al. Prevalence and risk factors of depressive disorder in caregivers of patients with head and neck cancer. Psychooncology 2015;24:155-61.

60. Bachem R, Casey P. Adjustment disorder: A diagnosis whose time has come. J Affect Disord 2018;227:243-53.

61. Johnson RJ, 3rd. A research study review of effectiveness of treatments for psychiatric conditions common to endstage cancer patients: needs assessment for future research and an impassioned plea. BMC Psychiatry 2018;18:85.

62. Shimizu K, Akizuki N, Nakaya N, et al. Treatment response to psychiatric intervention and predictors of response among cancer patients with adjustment disorders. J Pain Symptom Manage 2011;41:684-91.

63. van Beek FE, Wijnhoven LMA, Jansen F, et al. Prevalence of adjustment disorder among cancer patients, and the reach, effectiveness, cost-utility and budget impact of tailored psychological treatment: study protocol of a randomized controlled trial. BMC Psychol 2019;7:89.

64. Angelino AF, Treisman GJ. Major depression and demoralization in cancer patients: diagnostic and treatment considerations. Support Care Cancer 2001;9:344-9.

65. de Vries M, Stiefel F. Psychotherapy in the Oncology Setting. Recent Results Cancer Res 2018;210:145-61.

66. Brocken P, Prins JB, Dekhuijzen PN, et al. The faster the better?-A systematic review on distress in the diagnostic phase of suspected cancer, and the influence of rapid diagnostic pathways. Psychooncology 2012;21:1-10.

67. Hack TF, Pickles T, Ruether JD, et al. Predictors of distress and quality of life in patients undergoing cancer therapy: impact of treatment type and decisional role. Psychooncology 2010;19:606-16.

68. Mosher CE, Redd WH, Rini CM, et al. Physical, psychological, and social sequelae following hematopoietic stem cell transplantation: a review of the literature. 
Psychooncology 2009;18:113-27.

69. Andrykowski MA, Cordova MJ, Studts JL, et al. Posttraumatic stress disorder after treatment for breast cancer: prevalence of diagnosis and use of the PTSD Checklist-Civilian Version (PCL-C) as a screening instrument. J Consult Clin Psychol 1998;66:586-90.

70. Cordova MJ, Cunningham LL, Carlson CR, et al. Posttraumatic growth following breast cancer: a controlled comparison study. Health Psychol 2001;20:176-85.

71. Andrykowski MA, Steffens RF, Bush HM, et al. Lung Cancer Diagnosis and Treatment as a Traumatic Stressor in DSM-IV and DSM-5: Prevalence and Relationship to Mental Health Outcomes. J Trauma Stress 2015;28:206-13.

72. Mulligan EA, Wachen JS, Naik AD, et al. Cancer as a Criterion A Traumatic Stressor for Veterans: Prevalence and Correlates. Psychol Trauma 2014;6:S73-81.

73. Abbey G, Thompson SB, Hickish T, et al. A meta-analysis of prevalence rates and moderating factors for cancerrelated post-traumatic stress disorder. Psychooncology 2015;24:371-81.

74. Shelby RA, Golden-Kreutz DM, Andersen BL. PTSD diagnoses, subsyndromal symptoms, and comorbidities contribute to impairments for breast cancer survivors. J Trauma Stress 2008;21:165-72.

75. Ozer EJ, Best SR, Lipsey TL, et al. Predictors of posttraumatic stress disorder and symptoms in adults: a meta-analysis. Psychol Bull 2003;129:52-73.

76. Yehuda R. Hypothalamic-pituitary-adrenal alterations in PTSD: are they relevant to understanding cortisol alterations in cancer? Brain Behav Immun 2003;17 Suppl 1:S73-83.

77. Birk JL, Sumner JA, Haerizadeh M, et al. Early interventions to prevent posttraumatic stress disorder symptoms in survivors of life-threatening medical events: A systematic review. J Anxiety Disord 2019;64:24-39.

78. Girgenti MJ, Hare BD, Ghosal S, et al. Molecular and Cellular Effects of Traumatic Stress: Implications for PTSD. Curr Psychiatry Rep 2017;19:85.

79. Szeszko PR, Lehrner A, Yehuda R. Glucocorticoids and Hippocampal Structure and Function in PTSD. Harv Rev Psychiatry 2018;26:142-57.

80. Liang J, Lee SJ, Storer BE, et al. Rates and Risk Factors for Post-Traumatic Stress Disorder Symptomatology among Adult Hematopoietic Cell Transplant Recipients and Their Informal Caregivers. Biol Blood Marrow Transplant 2019;25:145-50.
81. Jia M, Li J, Chen C, et al. Post-traumatic stress disorder symptoms in family caregivers of adult patients with acute leukemia from a dyadic perspective. Psychooncology 2015;24:1754-60.

82. Rumpold T, Schur S, Amering M, et al. Informal caregivers of advanced-stage cancer patients: Every second is at risk for psychiatric morbidity. Support Care Cancer 2016;24:1975-82.

83. Posluszny DM, Dougall AL, Johnson JT, et al. Posttraumatic stress disorder symptoms in newly diagnosed patients with head and neck cancer and their partners. Head Neck 2015;37:1282-9.

84. Moschopoulou E, Hutchison I, Bhui K, et al. Posttraumatic stress in head and neck cancer survivors and their partners. Support Care Cancer 2018;26:3003-11.

85. Richardson AE, Morton RP, Broadbent EA. Illness perceptions and coping predict post-traumatic stress in caregivers of patients with head and neck cancer. Support Care Cancer 2016;24:4443-50.

86. Baider L, Goldzweig G, Ever-Hadani P, et al. Breast cancer and psychological distress: mothers' and daughters' traumatic experiences. Support Care Cancer 2008;16:407-14.

87. Kangas M, Milross C, Taylor A, et al. A pilot randomized controlled trial of a brief early intervention for reducing posttraumatic stress disorder, anxiety and depressive symptoms in newly diagnosed head and neck cancer patients. Psychooncology 2013;22:1665-73.

88. DuHamel KN, Mosher CE, Winkel G, et al. Randomized clinical trial of telephone-administered cognitivebehavioral therapy to reduce post-traumatic stress disorder and distress symptoms after hematopoietic stem-cell transplantation. J Clin Oncol 2010;28:3754-61.

89. Beatty L, Koczwara B. An effectiveness study of a CBT group program for women with breast cancer. Clin Psychol 2010;14:45-53.

90. Classen C, Butler LD, Koopman C, et al. Supportiveexpressive group therapy and distress in patients with metastatic breast cancer: a randomized clinical intervention trial. Arch Gen Psychiatry 2001;58:494-501.

91. Antoni MH, Wimberly SR, Lechner SC, et al. Reduction of cancer-specific thought intrusions and anxiety symptoms with a stress management intervention among women undergoing treatment for breast cancer. Am J Psychiatry 2006;163:1791-7.

92. Jarero I, Artigas L, Uribe S, et al. Pilot research study on the provision of the eye movement desensitization and 
reprocessing integrative group treatment protocol with female cancer patients. J EMDR Pract Res 2015;9:98-105.

93. El-Jawahri A, LeBlanc T, VanDusen H, et al. Effect of Inpatient Palliative Care on Quality of Life 2 Weeks After Hematopoietic Stem Cell Transplantation: A Randomized Clinical Trial. JAMA 2016;316:2094-103.

94. El-Jawahri A, Traeger L, Greer JA, et al. Effect of Inpatient Palliative Care During Hematopoietic StemCell Transplant on Psychological Distress 6 Months After Transplant: Results of a Randomized Clinical Trial. J Clin Oncol 2017;35:3714-21.

95. Feldman DB, Sorocco KH, Bratkovich KL. Treatment of posttraumatic stress disorder at the end-of-life: application of the Stepwise Psychosocial Palliative Care model. Palliat Support Care 2014;12:233-43.

96. Carson SS, Cox CE, Wallenstein S, et al. Effect of Palliative Care-Led Meetings for Families of Patients With Chronic Critical Illness: A Randomized Clinical Trial. JAMA 2016;316:51-62.

97. Kangas M, Henry JL, Bryant RA. Posttraumatic stress disorder following cancer. A conceptual and empirical review. Clin Psychol Rev 2002;22:499-524.

98. Rustad JK, David D, Currier MB. Cancer and posttraumatic stress disorder: diagnosis, pathogenesis and treatment considerations. Palliat Support Care 2012;10:213-23.

99. Renovanz M, Soebianto S, Tsakmaklis H, et al. Evaluation of the psychological burden during the early disease trajectory in patients with intracranial tumors by the ultrabrief Patient Health Questionnaire for Depression and Anxiety (PHQ-4). Support Care Cancer 2019;27:4469-77.

100.Bunevicius A, Deltuva V, Tamasauskas S, et al. Screening for psychological distress in neurosurgical brain tumor patients using the Patient Health Questionnaire-2. Psychooncology 2013;22:1895-900.

101.Esser P, Hartung TJ, Friedrich M, et al. The Generalized Anxiety Disorder Screener (GAD-7) and the anxiety module of the Hospital and Depression Scale (HADS-A) as screening tools for generalized anxiety disorder among cancer patients. Psychooncology 2018;27:1509-16.

102. Association AP. Diagnostic and Statistical Manual of Mental Disorders. 5th edition. Washington, DC: American Psychiatric Assocation Press, 2013.

103. Compton P, Chang YP. Substance Abuse and Addiction: Implications for Pain Management in Patients with Cancer. Clin J Oncol Nurs 2017;21:203-9.

104. Tan PD, Barclay JS, Blackhall LJ. Do Palliative Care Clinics Screen for Substance Abuse and Diversion? Results of a National Survey. J Palliat Med 2015;18:752-7.

105. Simard S, Thewes B, Humphris G, et al. Fear of cancer recurrence in adult cancer survivors: a systematic review of quantitative studies. J Cancer Surviv 2013;7:300-22.

106. Baumeister H, Kufner K. It is time to adjust the adjustment disorder category. Curr Opin Psychiatry 2009;22:409-12.

107. Casey P. Adjustment disorder: new developments. Curr Psychiatry Rep 2014;16:451.

108. Rayner L, Loge JH, Wasteson E, et al. The detection of depression in palliative care. Curr Opin Support Palliat Care 2009;3:55-60.

109. National Comprehensive Cancer Network. NCCN clinical practice guidelines in oncology (NCCN guidelines): Distress management. 2016. Available online: https://www. nccn.org/professionals/physician_gls/pdf/distress.pdf. Accessed January 182020.

110. Holland JC. Preliminary guidelines for the treatment of distress. Oncology (Williston Park) 1997;11:109-14; discussion 115-7.

111.Holland JC, Andersen B, Breitbart WS, et al. Distress management. J Natl Compr Canc Netw 2013;11:190-209.

112.Jacobsen PB, Andrykowski MA. Tertiary prevention in cancer care: understanding and addressing the psychological dimensions of cancer during the active treatment period. Am Psychol 2015;70:134-45.

113. Coelho A, de Brito M, Barbosa A. Caregiver anticipatory grief: phenomenology, assessment and clinical interventions. Curr Opin Support Palliat Care 2018;12:52-7.

114. Robinson S, Kissane DW, Brooker J, et al. A systematic review of the demoralization syndrome in individuals with progressive disease and cancer: a decade of research. J Pain Symptom Manage 2015;49:595-610.

115. Brewer BW, Caspari JM, Youngwerth J, et al. Demoralization in medical illness: Feasibility and acceptability of a pilot educational intervention for inpatient oncology nurses. Palliat Support Care 2018;16:503-10.

116. Tecuta L, Tomba E, Grandi S, et al. Demoralization: a systematic review on its clinical characterization. Psychol Med 2015;45:673-91.

117. Goebel S, von Harscher M, Mehdorn HM. Comorbid mental disorders and psychosocial distress in patients with brain tumours and their spouses in the early treatment phase. Support Care Cancer 2011;19:1797-805.

118. Goebel S, Stark AM, Kaup L, et al. Distress in patients with newly diagnosed brain tumours. Psychooncology 2011;20:623-30. 
119.Goebel S, Mehdorn HM. Fear of disease progression in adult ambulatory patients with brain cancer: prevalence and clinical correlates. Support Care Cancer 2019;27:3521-9.

120. Pranckeviciene A, Deltuva VP, Tamasauskas A, et al. Association between psychological distress, subjective cognitive complaints and objective neuropsychological functioning in brain tumor patients. Clin Neurol Neurosurg 2017;163:18-23.

121.Pranckeviciene A, Tamasauskas S, Deltuva VP, et al. Suicidal ideation in patients undergoing brain tumor surgery: prevalence and risk factors. Support Care Cancer 2016;24:2963-70.

122. Bruce M, Gumley D, Isham L, et al. Post-traumatic stress symptoms in childhood brain tumour survivors and their parents. Child Care Health Dev 2011;37:244-51.

123.Lu D, Andersson TM, Fall K, et al. Clinical Diagnosis of Mental Disorders Immediately Before and After Cancer Diagnosis: A Nationwide Matched Cohort Study in Sweden. JAMA Oncol 2016;2:1188-96.

124. Noh T, Walbert T. Brain metastasis: clinical manifestations, symptom management, and palliative care. Handb Clin Neurol 2018;149:75-88.

125.Durand T, Berzero G, Bompaire F, et al. Episodic Memory Impairments in Primary Brain Tumor Patients. Arch Clin Neuropsychol 2018;33:949-55.

126. Szepesi Z, Manouchehrian O, Bachiller S, et al. Bidirectional Microglia-Neuron Communication in Health and Disease. Front Cell Neurosci 2018;12:323.

127. Brites D, Fernandes A. Neuroinflammation and Depression: Microglia Activation, Extracellular Microvesicles and microRNA Dysregulation. Front Cell Neurosci 2015;9:476.

128. Skaper SD, Facci L, Giusti P. Neuroinflammation, microglia and mast cells in the pathophysiology of neurocognitive disorders: a review. CNS Neurol Disord Drug Targets 2014;13:1654-66.

129. Kulason KO, Schneider JR, Rahme R, et al. Lesional Temporal Lobe Epilepsy: Beware the Deceitful "Panic Attack". World Neurosurg 2018;111:197-200.

130. Richter A, Woernle CM, Krayenbuhl N, et al. Affective Symptoms and White Matter Changes in Brain Tumor Patients. World Neurosurg 2015;84:927-32.

131. Taku N, Gurnell M, Burnet N, et al. Time Dependence of Radiation-induced Hypothalamic-Pituitary Axis Dysfunction in Adults Treated for Non-pituitary, Intracranial Neoplasms. Clin Oncol (R Coll Radiol) 2017;29:34-41.
132. Lacroix A, Feelders RA, Stratakis CA, et al. Cushing's syndrome. Lancet 2015;386:913-27.

133. Kelly WF. Psychiatric aspects of Cushing's syndrome. QJM 1996;89:543-51.

134. Weitzner MA, Kanfer S, Booth-Jones M. Apathy and pituitary disease: it has nothing to do with depression. J Neuropsychiatry Clin Neurosci 2005;17:159-66.

135. Boone M, Roussel M, Chauffert B, et al. Prevalence and profile of cognitive impairment in adult glioma: a sensitivity analysis. J Neurooncol 2016;129:123-30.

136. Habets EJJ, Hendriks EJ, Taphoorn MJB, et al. Association between tumor location and neurocognitive functioning using tumor localization maps. J Neurooncol 2019;144:573-82.

137.Ali FS, Hussain MR, Gutierrez C, et al. Cognitive disability in adult patients with brain tumors. Cancer Treat Rev 2018;65:33-40.

138. Hendrix P, Hans E, Griessenauer CJ, et al. Neurocognitive status in patients with newly-diagnosed brain tumors in good neurological condition: The impact of tumor type, volume, and location. Clin Neurol Neurosurg 2017;156:55-62.

139. Jacob J, Durand T, Feuvret L, et al. Cognitive impairment and morphological changes after radiation therapy in brain tumors: A review. Radiother Oncol 2018;128:221-8.

140. Makale MT, McDonald CR, Hattangadi-Gluth JA, et al. Mechanisms of radiotherapy-associated cognitive disability in patients with brain tumours. Nat Rev Neurol 2017;13:52-64.

141. Corti C, Urgesi C, Massimino M, et al. Effects of supratentorial and infratentorial tumor location on cognitive functioning of children with brain tumor. Childs Nerv Syst 2020;36:513-24.

142. Rooney AG, Carson A, Grant R. Depression in cerebral glioma patients: a systematic review of observational studies. J Natl Cancer Inst 2011;103:61-76.

143. Ismail Z, Elbayoumi H, Fischer CE, et al. Prevalence of Depression in Patients With Mild Cognitive Impairment: A Systematic Review and Meta-analysis. JAMA Psychiatry 2017;74:58-67.

144. Srivastava S, Bhatia MS, Gaur A, et al. Psychiatric and cognitive correlates of quality of life among persons with primary brain tumors. Ind Psychiatry J 2019;28:141-7.

145. Nicol C, Ownsworth T, Cubis L, et al. Subjective cognitive functioning and associations with psychological distress in adult brain tumour survivors. J Cancer Surviv 2019;13:653-62.

146. Kosse NM, de Groot MH, Vuillerme N, et al. Factors 
related to the high fall rate in long-term care residents with dementia. Int Psychogeriatr 2015;27:803-14.

147.Posti JP, Bori M, Kauko T, et al. Presenting symptoms of glioma in adults. Acta Neurol Scand 2015;131:88-93.

148. Rahman Z, Wong CH, Dexter M, et al. Epilepsy in patients with primary brain tumors: The impact on mood, cognition, and HRQOL. Epilepsy Behav 2015;48:88-95.

149. Avila EK, Graber J. Seizures and epilepsy in cancer patients. Curr Neurol Neurosci Rep 2010;10:60-7.

150.van Breemen MS, Wilms EB, Vecht CJ. Epilepsy in patients with brain tumours: epidemiology, mechanisms, and management. Lancet Neurol 2007;6:421-30.

151.Pace A, Bove L, Innocenti P, et al. Epilepsy and gliomas: incidence and treatment in 119 patients. J Exp Clin Cancer Res 1998;17:479-82.

152. Carmassi C, Corsi M, Gesi C, et al. DSM-5 criteria for PTSD in parents of pediatric patients with epilepsy: What are the changes with respect to DSM-IV-TR? Epilepsy Behav 2017;70:97-103.

153.Lane C, Crocker C, Legg K, et al. Anxiety and Depression in Adult First Seizure Presentations. Can J Neurol Sci 2018;45:144-9.

154. Dehn LB, Pfafflin M, Bruckner S, et al. Relationships of depression and anxiety symptoms with seizure frequency: Results from a multicenter follow-up study. Seizure 2017;53:103-9.

155.Ettinger AB, Reed ML, Goldberg JF, et al. Prevalence of bipolar symptoms in epilepsy vs other chronic health disorders. Neurology 2005;65:535-40.

156. Kanner AM. Depression in epilepsy: a neurobiologic perspective. Epilepsy Curr 2005;5:21-7.

157.Beyenburg S, Mitchell AJ, Schmidt D, et al. Anxiety in patients with epilepsy: systematic review and suggestions for clinical management. Epilepsy Behav 2005;7:161-71.

158. Dussaule C, Bouilleret V. Psychiatric effects of antiepileptic drugs in adults. Geriatr Psychol Neuropsychiatr Vieil 2018;16:181-8.

159. Bedetti C, Romoli M, Maschio M, et al. Neuropsychiatric adverse events of antiepileptic drugs in brain tumourrelated epilepsy: an Italian multicentre prospective observational study. Eur J Neurol 2017;24:1283-9.

160. Knudsen-Baas KM, Johannesen TB, Myklebust TA, et al. Antiepileptic and psychiatric medication in a nationwide cohort of patients with glioma WHO grade II-IV. J Neurooncol 2018;140:739-48.

161. Glantz MJ, Cole BF, Forsyth PA, et al. Practice parameter: anticonvulsant prophylaxis in patients with newly diagnosed brain tumors. Report of the Quality Standards
Subcommittee of the American Academy of Neurology. Neurology 2000;54:1886-93.

162. Mula M. The pharmacological management of psychiatric comorbidities in patients with epilepsy. Pharmacol Res 2016;107:147-53.

163. Trivedi MH, Kurian BT. Managing depressive disorders in patients with epilepsy. Psychiatry (Edgmont) 2007;4:26-34.

164. Kanner AM. Most antidepressant drugs are safe for patients with epilepsy at therapeutic doses: A review of the evidence. Epilepsy Behav 2016;61:282-6.

165. Ryken TC, McDermott M, Robinson PD, et al. The role of steroids in the management of brain metastases: a systematic review and evidence-based clinical practice guideline. J Neurooncol 2010;96:103-14.

166. Chang SM, Messersmith H, Ahluwalia M, et al. Anticonvulsant prophylaxis and steroid use in adults with metastatic brain tumors: summary of SNO and ASCO endorsement of the Congress of Neurological Surgeons guidelines. Neuro Oncol 2019;21:424-7.

167. Brown ES, Chandler PA. Mood and Cognitive Changes During Systemic Corticosteroid Therapy. Prim Care Companion J Clin Psychiatry 2001;3:17-21.

168. Fardet L, Petersen I, Nazareth I. Suicidal behavior and severe neuropsychiatric disorders following glucocorticoid therapy in primary care. Am J Psychiatry 2012;169:491-7.

169. Bolanos SH, Khan DA, Hanczyc M, et al. Assessment of mood states in patients receiving long-term corticosteroid therapy and in controls with patient-rated and clinicianrated scales. Ann Allergy Asthma Immunol 2004;92:500-5.

170. Minden SL, Orav J, Schildkraut JJ. Hypomanic reactions to ACTH and prednisone treatment for multiple sclerosis. Neurology 1988;38:1631-4.

171. Naber D, Sand P, Heigl B. Psychopathological and neuropsychological effects of 8-days' corticosteroid treatment. A prospective study. Psychoneuroendocrinology 1996;21:25-31.

172. Hodgkiss A. Biological Psychiatry of Cancer and Cancer Treatment. Oxford University Press, 2016.

173. Collado-Borrell R, Escudero-Vilaplana V, RomeroJimenez R, et al. Oral antineoplastic agent interactions with medicinal plants and food: an issue to take into account. J Cancer Res Clin Oncol 2016;142:2319-30.

174. Wang Q, Qi F, Song X, et al. A prospective longitudinal evaluation of cognition and depression in postoperative patients with high-grade glioma following radiotherapy and chemotherapy. J Cancer Res Ther 2018;14:S1048-51.

175. Ruis C, Wajer IH, Robe P, et al. Anxiety in the preoperative phase of awake brain tumor surgery. Clin 
Neurol Neurosurg 2017;157:7-10.

176.Jenkins LM, Drummond KJ, Andrewes DG. Emotional and personality changes following brain tumour resection. J Clin Neurosci 2016;29:128-32.

177. Goebel S, Mederer D, Mehdorn HM. Surgery-Related Coping in Surgery Patients with Intracranial Tumors. World Neurosurg 2018;116:e775-82.

178. Hadidchi S, Surento W, Lerner A, et al. Headache and Brain Tumor. Neuroimaging Clin N Am 2019;29:291-300.

179. Nelson S, Taylor LP. Headaches in brain tumor patients: primary or secondary? Headache 2014;54:776-85.

180. Ansari H, Kouti L. Drug Interaction and Serotonin Toxicity with Opioid Use: Another Reason to Avoid Opioids in Headache and Migraine Treatment. Curr Pain Headache Rep 2016;20:50.

181. Goebel S, Mehdorn HM. Measurement of psychological distress in patients with intracranial tumours: the NCCN distress thermometer. J Neurooncol 2011;104:357-64.

182. Arnold SD, Forman LM, Brigidi BD, et al. Evaluation and characterization of generalized anxiety and depression in patients with primary brain tumors. Neuro Oncol 2008;10:171-81.

183. Ularntinon S, Tzuang D, Dahl G, et al. Concurrent treatment of steroid-related mood and psychotic symptoms with risperidone. Pediatrics 2010;125:e1241-5.

184. Ross S. Therapeutic use of classic psychedelics to treat cancer-related psychiatric distress. Int Rev Psychiatry 2018;30:317-30.

Cite this article as: Gibson AW, Graber JJ. Distinguishing and treating depression, anxiety, adjustment, and post-traumatic stress disorders in brain tumor patients. Ann Palliat Med 2021;10(1):875-892. doi: 10.21037/apm-20-509
185.Fan W, Yang H, Sun Y, et al. Ketamine rapidly relieves acute suicidal ideation in cancer patients: a randomized controlled clinical trial. Oncotarget 2017;8:2356-60.

186. Iglewicz A, Morrison K, Nelesen RA, et al. Ketamine for the treatment of depression in patients receiving hospice care: a retrospective medical record review of thirty-one cases. Psychosomatics 2015;56:329-37.

187.Zhou Y, Peng Y, Fang J, et al. Effect of low-dose ketamine on PerioperAtive depreSsive Symptoms in patients undergoing Intracranial tumOr resectioN (PASSION): study protocol for a randomized controlled trial. Trials 2018;19:463.

188. Kangas M. Psychotherapy Interventions for Managing Anxiety and Depressive Symptoms in Adult Brain Tumor Patients: A Scoping Review. Front Oncol 2015;5:116.

189.Xiao N, Zhu D, Xiao S. Effects of continued psychological care toward brain tumor patients and their family members' negative emotions. J Cancer Res Ther 2018;14:S202-7.

190. Bunevicius A. Personality traits, patient-centered health status and prognosis of brain tumor patients. J Neurooncol 2018;137:593-600.

191. Keeling M, Bambrough J, Simpson J. Depression, anxiety and positive affect in people diagnosed with low-grade tumours: the role of illness perceptions. Psychooncology 2013;22:1421-7.

192. Walbert T, Chasteen K. Palliative and supportive care for glioma patients. Cancer Treat Res 2015;163:171-84. 